\title{
Pre-peritonial Repair for Recurrent Inguinal Hernia after Tension free Hernioplasty
}

Suresh Raj Paudel ${ }^{1}$, Narendra Vikram Gurung ${ }^{1}$, Dhruba Bahadur Adhikari ${ }^{1}$, Arjun Acharya ${ }^{1}$, Santosh Shrestha $^{1}$, Amar Gurung ${ }^{1}$, Debendra Shrestha ${ }^{1}$, Amrita Ghimire Paudel ${ }^{2}$, Bishwo Raj Baral ${ }^{3}$, Dilip Baral ${ }^{1}$

${ }^{1}$ Department of Surgery, Pokhara Academy of Health Sciences, Western Regional Hospital.

${ }^{2}$ Department of Pediatric, Pokhara Academy of Health Sciences, Western Regional Hospital.

${ }^{3}$ Department of Internal medicine, Pokhara Academy of Health Sciences, Western Regional Hospital.

\section{Correspondence:}

Dr. Suresh Raj Paudel, MS,

Pokhara Academy of Health Sciences,

Western Regional Hospital, Pokhara

Nepal

Email: poudelsuresh6@gmail.com

Article received : $5^{\text {th }}$ May 2018

Article accepted : $24^{\text {th }}$ July 2018

\section{ABSTRACT}

\section{Background:}

Inguinal herniorrhaphy is a common general surgical operation. The repair of recurrent hernia is difficult surgery due to obscured and distorted anatomy and risk of further recurrence. The aim of this study is to determine the outcome in terms of operative time, hospital stay, return to work, complications and recurrence of open pre-peritoneal repair for recurrent inguinal hernias after Lichtenstein tension-free hernioplasty. Materials And Method: It is a prospective observational study conducted at Western Regional Hospital, Pokhara from 2013 to 2016. A total of eight patients including referred from other centers were included. Pre-peritoneal repair was performed on recurrent hernias after Lichtenstein tensionfree hernioplasty. Age, sex, operating time, hospital stay, time to return work, postoperative complications and recurrence of patients were noted. Statistical analysis was done using SPSS- 21. Patients were called for follow up in 2 weeks, 3 months and 12 months time. Results: Out of eight patients, seven were male, one was female with mean age of 59.5 years. Recurrence was common on direct inguinal hernia (six patients) who had previous Lichtenstein hernioplasty. Mean operative time was 43.13 minutes (35 to 50 minutes), mean hospital stay was 2.5 days ( 2 to 4 days) and mean time to return to work was 8.12 days ( 7 to 10 days). There was hematoma formation in one patient. Conclusion: Pre-peritoneal mesh repair is easy, safe, with less operative time, short hospital stay, low recurrence and complication rate for recurrent inguinal hernia after Lichtenstein hernioplasty.

Keywords - Hernia, Inguinal, Lichtenstein, Mesh, Preperitoneal

\section{INTRODUCTION}

Inguinal hernia surgery is common surgical operations.

Recurrance of inguinal hernia after mesh repair is very less (0 to $1 \%) .{ }^{1}$ Hernioplasty performed for recurrence was reported in nationwide large scale Danish study. ${ }^{2}$ 
There are many types of hernia repair reported in the literature. Tension free hernioplasty with placement of mesh is the most popular, easy and safe method to repair inguinal hernia. ${ }^{3}$ The Lichtenstein tensionfree hernioplasty is the gold standard of hernia repair. Obesity, old age, type of repair and postoperative complications of previous surgery are the important predisposing factors leading to recurrence of inguinal hernia surgery. There are dense fibrotic scar tissue, obscured and distorted anatomy due to previous surgery in recurrent hernia. So the risk of testicular damage and local hematoma formation is high in the repair of recurrent inguinal hernia. These facts make the repair of recurrent hernia a difficult surgery. There are no fixed guidelines acceptable to all surgeons on the optimal management of recurrent inguinal hernia after mesh repair. An optimal strategy and widely acceptable surgical technique is more important in the management of recurrent inguinal hernias than in other areas of hernia surgery. ${ }^{4}$

The posterior pre-peritoneal approach either by laparoscopic or open approach is the procedure of choice for the management of all recurrent groin hernias. ${ }^{5}$ The surgery is done through the fresh area in posterior pre-peritonial approach and mesh is fixed in pre-peritoneal space. This approach exclude the operation through dense adhesive fibrous tissue due to previous surgery and make it better then anterior approach. Laparoscopic pre-peritoneal hernia repair is the gold standard for inguinal hernia repair where these fascilities are available. ${ }^{6}$ It has many advantages like less hospital stay, less postoperative pain and recurrence rates. Laparoscopic repair is more expensive. It requires experienced surgeon and longer learning curve. The open posterior pre-peritoneal repair is easy, safe and can be performed by every general surgeon. So it is a good alternative for recurrent inguinal hernias. ${ }^{7}$

The aim of this study is to determine the factors like operating time, hospital stay, return to work and complications like hematoma, seroma, wound infection, mesh infection, chronic pain, testicular atrophy and recurrence after open pre-peritoneal repair for recurrent inguinal hernia.

\section{MATERIAL AND METHOD}

This is a prospective study conducted at western regional hospital, Pokhara from 2013 to 2016 after taking ethical clearance from hospital. A total of eight patients were included in the study. All patients of recurrent inguinal hernia (previously repaired with Lichtenstein tension free repair ), who presented in out patient department in the study period were enrolled. Patients age, sex, hospital stay, operative time, time to return work, type of hernia, post-operative complications were noted if present. Patients were called for follow up in 2 weeks, 3 months and 12 months and asked for any complain. If needed clinical examination and ultrasonography were done in follow up.

The open pre-peritoneal approach to the recurrent inguinal hernia was performed under general or regional anesthesia. A lower abdominal transverse incision was given. The anterior rectus sheath was opened. Rectus muscle retracted medially. The pre-peritoneal space was created with blunt dissection exposing the myopectineal orifice. The cord was explored and hernias was reduced. A polypropylene mesh of size $15 / 10 \mathrm{~cm}$ with a slit was inserted in preperitonial space and fixed with non-absorbable sutures to pubic tubercle and Cooper's ligament. Statistical analysis was done using Microsoft Excel software and SPSS-21. Result obtained from the study was discussed with reference to current world literature.

\section{RESULTS}

Eight patients were enrolled in the study. Seven were male and one was female. Male: female ratio was 7:1. Youngest patient was 35 years old and eldest was 75 year. Mean age is 59.5 years.

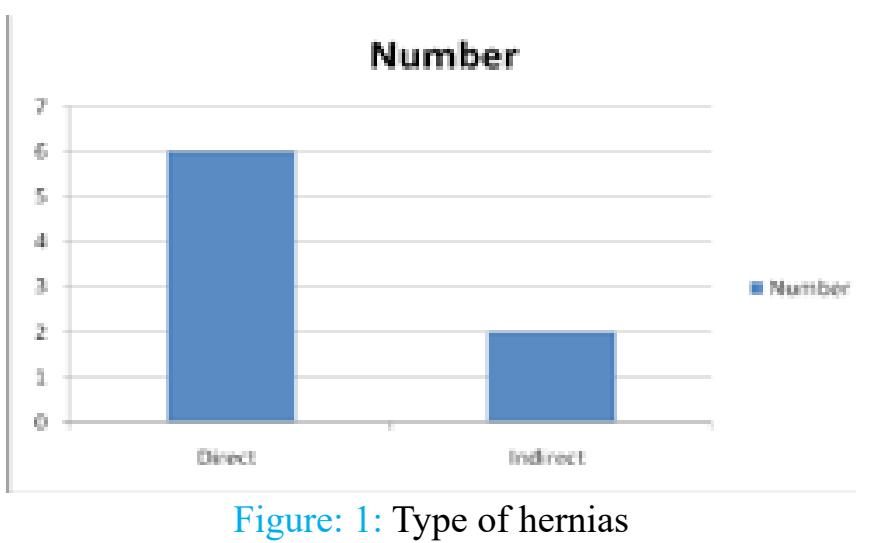

In our study pre-peritoneal mesh repair were done in 6 patients with recurrent direct inguinal hernia and 2 indirect recurrent inguinal hernia (figure 1). It has 
shown that recurrence was common in direct hernia after Lichtenstein tension free repair.

\section{Table 1: Demographic data}

\begin{tabular}{|l|c|c|c|c|}
\hline Parameters & Minimum & Maximum & Mean & $\begin{array}{c}\text { Std. } \\
\text { Deviation }\end{array}$ \\
\hline $\begin{array}{l}\text { Operative } \\
\text { time(minute) }\end{array}$ & 35 & 50 & 43.13 & 5.303 \\
\hline $\begin{array}{l}\text { Hospital } \\
\text { stay(days) }\end{array}$ & 2 & 4 & 2.50 & .756 \\
\hline $\begin{array}{l}\text { Time to return } \\
\text { to work }\end{array}$ & 7 & 10 & 8.12 & 1.246 \\
\hline (days) & & & & \\
\hline
\end{tabular}

The mean operative time was 43.13 minutes ( 35 to 50 ) with standard deviation of 5.303. Mean hospital stay was 2.5 days ( 2 to 4 days) with standard deviation of 0.756 . Mean time to return to work was 8.12 (7 to 10 days) with standard deviation of 1.246 .

\section{Table 2: Complications}

\begin{tabular}{|c|c|}
\hline Complications & Number \\
\hline Hematoma & 1 \\
\hline Seroma & 0 \\
\hline Wound infection & 0 \\
\hline Chronic pain & 0 \\
\hline Testicular atrophy & 0 \\
\hline Reccurence & 0 \\
\hline
\end{tabular}

Regarding postoperative complications, only one patient developed haematoma which resolved after two weeks. Other complications were not seen in our study.

\section{DISCUSSION}

Lichtenstein hernioplasty is the gold standard of hernia repair. It is simple, safe with low morbidity and recurrence rate less than $1 \%$. The operation of recurrent inguinal hernia after mesh repair is a difficult surgery. ${ }^{8}$ Dense fibrotic scar tissue are formed around the mesh of previous surgery. These tissue increases the risk of testicular damage and formation of local hematoma. So the surgery for recurrent hernia through anterior approach is difficult. The open posterior pre-peritoneal mesh repair was popularized by Nhyus ${ }^{6}$ It is a good alternative for recurrent inguinal hernias repair . In preperitoneal approach mesh is placed in the pre-peritoneal space where the hernia is produced. This avoids the reoperation through scar tissue. From the molecular point of view the pre-peritoneal space appears less invasive than the trans-inguinal anterior approach. The production of tumor necrosis factors (TNF) alpha levels are highest in the open anterior group which make the tissues more dense and fibrotic . ${ }^{6}$

In this study we observed that seventy five percentage of direct hernia reoccurred after primary mesh repair which was similar to the study by Nordin PP, Haapaniemi S, Vander L W, Nilsson E. ${ }^{9}$ Recurrence can occur very soon in a week after the primary operation or it can develop much later on (even after five years). ${ }^{10}$ In our study we found that the open posterior pre-peritoneal approach in recurrent hernia repair had less time of hospital stay (2.5 days), less operative time(43.13 minutes) and early return to work (8.12 days) after surgery. This study is similar to study by Günal $\mathrm{O}$, Ozer S, Gürleyik E, Bahçebaşi T et al. ${ }^{11}$

Surgery for a recurrent hernia has a higher incidence of chronic pain in comparison to primary hernioplasty. Chronic pain is less common with open posterior than anterior approach. In posterior approach the risk of damage to testicular vessels, nerves and lymphatics is less as it avoids the distorted and scared tissues. ${ }^{12}$ The open posterior pre-peritoneal approach in the present study showed no chronic pain which is similar to above study. Another study by Farooq O, Bashir also concluded that Open preperitoneal repair for recurrent inguinal hernia is safe procedure as it eliminates testicular complications and has a very low recurrence rate. ${ }^{13}$

Early complications which are found after repair of recurrent hernia are wound seroma, sepsis, scrotal edema and hematoma formation and the long-term complications are testicular atrophy and recurrence. Hematoma was seen in one patient. There were no seroma formation, wound infection, chronic pain, testicular atrophy and recurrence in our study which is compairable with the study by Wright D, Paterson C, Scott N, et al ${ }^{14}$ where there were no testicular atrophy and recurrence. Testicular atrophy and necrosis occurs as a result of ischemic orchitis. It is a well-established complication after anterior inguinal hernia repair with $1 \%$ occurance following primary herniorrhaphy and $5 \%$ in recurrent cases. ${ }^{15}$ Open posterior pre-peritoneal repair decreases testicular complications and chronic pain due to operation through fresh area $^{16}$. There are collateral arterial flow to the testis from the inferior epigastric, vesical, prostatic and scrotal arteries. 
So testicular ischemia and necrosis is not due to arterial injury but is due to acute thrombosis of the pampiniform venous plexus. ${ }^{17}$ Testicular atrophy is more common after open anterior procedures in recurrent inguinal hernias than posterior procedure (laparoscopic or open). There will be greater manipulation of the spermatic cord beyond the pubic tubercle and during dissection of the distal hernia sac in anterior approach which increases the chance of damage to nerves, lymphatics and vessels leading to testicular atrophy.

\section{CONCLUSION}

Open preperitoneal mesh repair is easy to perform, safe to the patients with less operative time, short hospital stay and complication rate. It is highly effective in preventing re-reoccurance. It can be the procedure of choice for general surgeon for recurrent inguinal hernia repair after Lichtenstein hernioplasty.

\section{REFERRENCES}

1. Amid P.K , Shulman A.G, Lichtenstein I.L: Open 'tension free' repair of inguinal hernias, the Lichtenstein technique. Eur J Surg. 1996 Jun; 162(6):447-53.

2. Rosenberg $J$, Bisgaard $T$, Kehlet $H$, Wara $P$, Asmussen T, Juul P, Strand L, Andersen FH, BayNielsen M: Danish Hernia Database. Danish Hernia Database recommendations for the management of inguinal and femoral hernia in adults. Dan Med Bull 2011 Feb, 58(2):C4243.

3. Amid PK. Groin hernia repair: open techniques. World J Surg.2005 Aug; 29(8): 1046-51.

4. Campanelli G, Pettinari D, Nicolosi FM, Cavalli M, Avesani EC: Inguinal hernia recurrence: classification and approach. Hernia 2006 Apr; 10(2):159-61.

5. Nyhus LM, Pollak R, Bombeck CT, Donahue PE: The pre-peritoneal approach and prosthetic buttress repair for recurrent hernia. The evolution of a technique. Ann Surg 1988 Dec; 208(6):733-37.

6. Ramshaw B, Abiad F, Voeller G, Wilson R, Mason E. Polyester(Parietex) mesh for total extraperitoneal laparoscopic inguinal hernia repair. Initial experience in the United States. Surg Endosc.2003 Mar; 17(3): 498-501.

7. Nyhus LM. Iliopubic tract repair of inguinal and femoral hernia.The posterior (pre-peritoneal) approach. Surg Clin North Am.1993 Jun; 73(3): 487-99.

8. Katri KM: Open pre-peritoneal mesh repair of recurrent inguinal hernia. Hernia 2009 Dec; 13(6):585-89.

9. Nordin PP, Haapaniemi S, van Der Linden W, Nilsson E. Choice of anesthesia and risk of reoperation for recurrence in groin hernia repair. Ann Surg. 2004 Sept; 240:187-92.

10. Magnusson N, Nordin P, Hedberg M, Gunnarsson U, Sandblom G. The time profile of groin hernia recurrences. Hernia 2010 Aug;14(4): 341-44.

11. Günal $\mathrm{O}$, Ozer $\mathrm{S}$, Gürleyik E, Bahçebaşi T: Does the approach to the groin make a difference in hernia repair? Hernia 2007 Oct; 11(5):429-34.

12. Karatepe $\mathrm{O}$, Acet E, Altiok M, Adas G, Cakır A, Karahan S: Preperitoneal repair (open posterior approach) for recurrent inguinal hernias previously treated with Lichtenstein tension-free hernioplasty. Hippokratia 2010 Apr; 14(2):119 21.

13. Farooq O, Bashir-ur-Rehman .Recurrent inguinal hernia repair by open preperitoneal approach. J Coll Physicians Surg Pak. 2005 May;15(5):261-65.

14. Wright D, Paterson C, Scott N, et al: Five-year follow-up of patients undergoing laparoscopic or open groin hernia repair: a randomized controlled trial. Ann Surg 2002; 235(12):33337.

15. Chu L, Averch TD, Jackman SV: Testicular infarction as a sequela of inguinal hernia repair. Can J Urol 2009 Dec;16(6):4953-54.

16. Nienhuijs S, Staal E, Strobbe L, Rosman C, Groenewoud H, Bleichrodt R: Chronic pain after mesh repair of inguinal hernia: a systematic review. Am J Surg 2007 Sep; 194(3):394-400.

17. Moore JB, Hasenboehler EA: Orchiectomy as a result of ischemic orchitis after laparoscopic inguinal hernia repair: case report of a rare complication. Patient Saf Surg 2007 Nov; $7(1): 1-3$. 